\title{
Interview with Peter Piot
}

\section{Marc Vandenbruaene}

See linked editorial, p 425

This interview was conducted during the 17th ISSTDR and 10th IUSTI World Congress held in Seattle, Washington, 29 July to 1 August 2007.

Peter Piot gave the opening plenary presentation, "STIs and HIV: learning from each other for a longterm response". ${ }^{1-3}$

\section{Peter Piot-Executive Director of UNAIDS}

Peter Piot is Executive Director of the Joint United Nations Programme on HIV/AIDS (UNAIDS) and Under Secretary-General of the United Nations. Peter Piot trained in medicine and microbiology at the Universities of Ghent and Antwerp, Belgium and the University of Washington, Seattle, USA. Soon after graduating from medical school, he co-discovered the Ebola virus in 1976, while working at the Institute of Tropical Medicine in Antwerp, Belgium. Since the very first reports on AIDS, he has been a key player in the field of HIV. In the early 1980s, Peter Piot launched research projects in Africa (Burundi, Côte d'Ivoire, Kenya, Tanzania and Zaïre, now Democratic Republic of Congo). Projet SIDA in Kinshasa, Zairre, was the first international project on AIDS in Africa and provided the foundations of our current understanding of HIV infection in Africa. In 1992, Dr Piot joined the Global Programme on AIDS of the World Health Organization as Associate Director. Since the creation of UNAIDS in 1995, Peter Piot has been drawing his skills as scientist, manager and activist, focusing on AIDS and on women's health in developing countries. Under his leadership, UNAIDS has become the chief advocate for worldwide action against AIDS. This interview was conducted during the 17th ISSTDR and 10th IUSTI World Congress held in Seattle, Washington, 29 July to 1 August 2007 (fig 1). ${ }^{1}$ Peter Piot gave the opening plenary talk, "STIs and HIV: learning from each other for a long term response". ${ }^{\prime 2}$
STI: What made you present the data showing unsafe sex as the second most important cause of ill health in the world?

Peter Piot: Not many people know these data (fig 2). They come from the World Health Organization, World Health Report 2002. Rather than look at which illnesses are major causes of ill health measured as disability-adjusted life years (DALYs), epidemiologists looked at behaviours and risk factors. "Unsafe sex, what does it cause?" was their key question. Unsafe sex gives, of course, all kinds of STDs, pelvic inflammatory disease, cervical cancer, infertility and some of the neonatal complications like congenital syphilis. These data are not well published and well utilised. That's why I showed them yesterday.

It is well known that both sexual behaviour and the results of unsafe sex are not distributed in what we statistically call a "normal distribution". I don't like the word core group. It happens in populations. It can be migrant populations, it happens in men, injecting drugs users. It affects women more than men. It affects reproductive health. In terms of diversity, take Asia as an example. When you

\section{Box 1: Programmatic opportunities for} STI \& HIV/AIDS collaboration

- Integration of national and local programmes

- Joint training

- Joint monitoring and evaluation

- Joint education campaigns

- Integration of clinical services

- Counselling for prevention in clinic settings

- Routine offer of HIV testing to STI patients

- Syphilis testing in antenatal clinic attendees

Source: UNAIDS

\section{Dr Marc}

Vandenbruaene, Institute of Tropical Medicine, Antwerp, Nationalestraat 155 Antwerpen B-2000, Belgium; mvdbruaene@ itg.be

Accepted 17August 2007

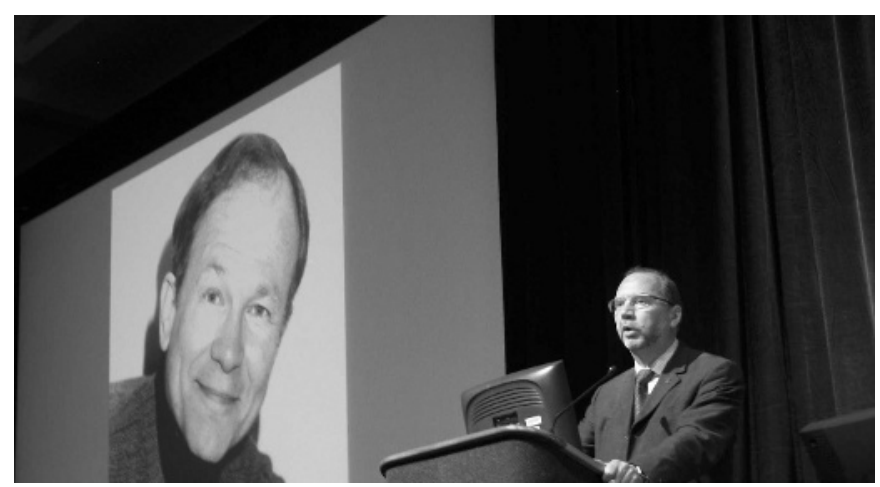

Figure 1 Peter Piot giving the opening plenary session of the 17th ISSTDR, 10th IUSTI World Congress in Seattle. Pictured in the background is a younger King Holmes, whose 70th birthday was honoured during the conference. Source: UNAIDS. 
take countrywide national prevalences of HIV, it can be $1 \%$ or less, but at the same time you can have populations, like men who have sex with men, where the prevalence can be $30-40 \%$. Averages are very misleading.

One of my other main points was the comparison of interest from the political world-interest in AIDS vs. STI. Without any doubt, AIDS has made it to the top of political agendas, but that's not at all the case for STDs.

STI: During this conference, the World Health Organization sponsored a symposium, "Global Strategy for STIs: partnership for implementation". Are STI and HIV programmes collaborating enough? Peter Piot: There are many missed opportunities for both HIV and STDs. In many countries, services are separated. Programmes are separated. I can give you a few examples. In PMTCT programmes, blood is tested for HIV in pregnant women, but far less for syphilis. Congenital syphilis is a major problem. We also have a missed opportunity when it comes to testing STD patients for HIV. That's not widely done. STD patients are of course a group with a very high risk of HIV. An example in the good sense is the UK clinical system, where STI physicians also see HIV patients. In many countries, that is not at all the case-in France, for instance, or in the Netherlands.

I can give several examples, but I think we need to integrate much more (box 1). On the other hand we don't need to integrate completely. HIV acquisition by injection drug use is totally out of the STI field. Some people say HIV and STD is just part of reproductive health. Well, gay men, by definition, are not part of reproductive health.

STI: Do we need a "UN-STI"?
Peter Piot: No. STI could be part of AIDS programmes in all countries. Combine them. When I came to WHO in 1992, one of my first jobs was to bring the STD programme, then called VDT, Venereal Diseases and Treponematosis, into the Global Programme on AIDS. Initially, it was successful, but then it stopped. WHO puts STI now under reproductive health. When I tried to get information on STI epidemiology for my talk yesterday, in WHO they said they don't have recent data. The last ones are from 1998. So, I went to King Holmes' group. That's not normal.

STI: On many occasions, you have said that you rephrased AIDS from a public health problem to an economical and a national security problem. What, or who, inspired you to take this route?

Peter Piot: First of all, I noticed that we didn't make any progress on AIDS in the first 15 years, from the 1980s on. Also, in the early years after the creation of UNAIDS, progress was very limited. I realised we were stuck. I asked around and brought together some people who were thinking more in political terms than me. Or than I used to do. From the beginning, when I got the job at UNAIDS, I was determined to put AIDS on the political agenda, but I didn't know how to do it. Part of it was to reposition AIDS. I think, in 2001 and 2002, many things came together. It is not just one thing. I noticed that when I talked to top leaders that the only things that really matters are "the economy, stupid", as Clinton said-and security.

STI: Can the same strategy be used to raise more political interest for STIs?

Peter Piot: I think we could do this for a number of things, particularly when you see the burden of STI on women (table 1). Just consider the

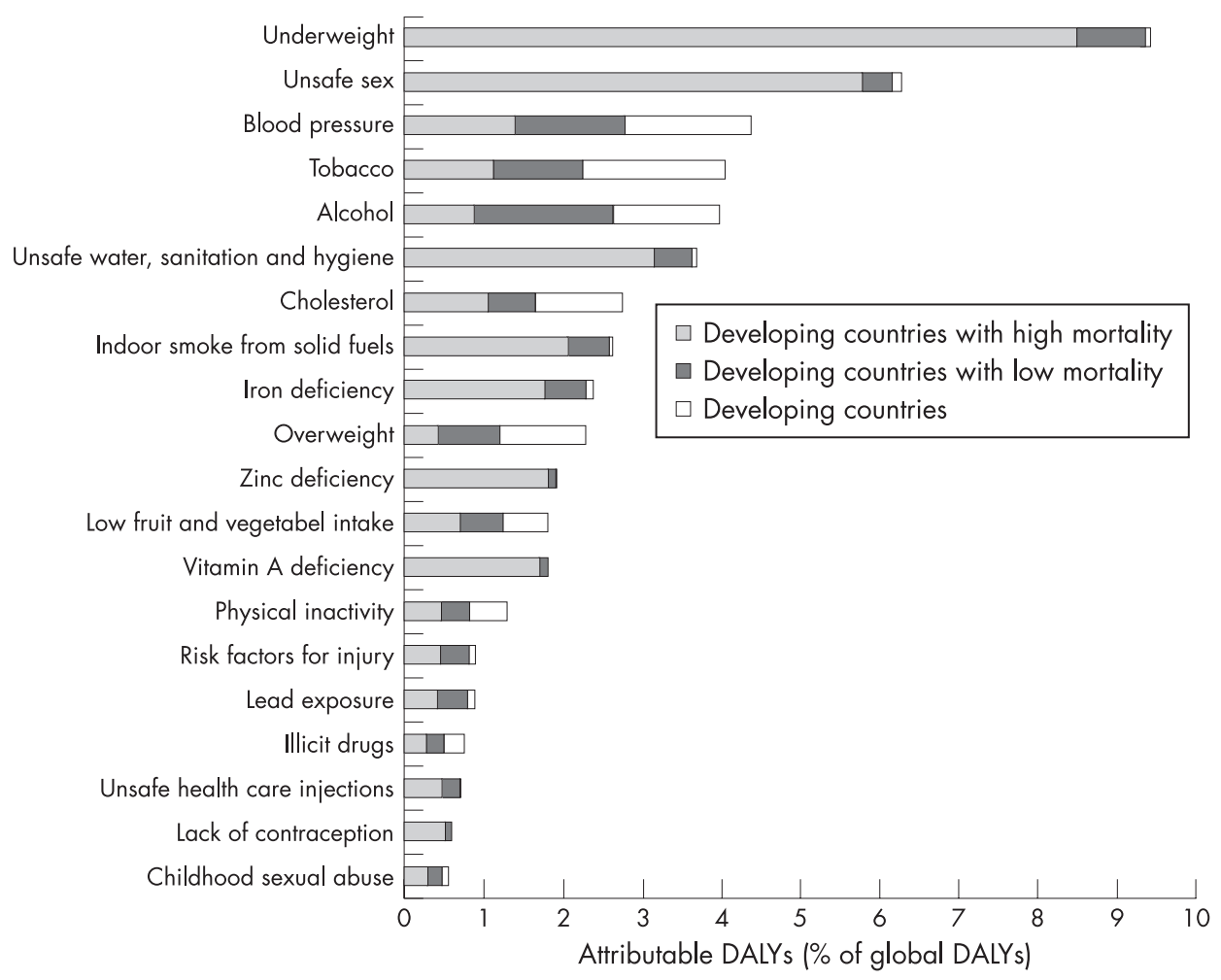

Figure 2 Global distribution of burden of disease attributable to 20 leading selected risk factors. Source: World Health Organization. The World Health Report 2002. Geneva: World Health Organization, 2002. 
Table 1 Elements influencing political agendas

\begin{tabular}{lll}
\hline & HIV/AIDS & STls \\
\hline New epidemic & +++ & + \\
Stigma & +++ & + \\
Mortality & ++++ & + \\
Burden on women & ++ & +++ \\
Effective interventions & ++ & +++ \\
Activism & +++ & - \\
Interest in media & ++ & $+/-$ \\
Economic impact & +++ & ++ \\
Security impact & + & $+/-$ \\
International leadership & +++ & $+/-$ \\
and coordination & & \\
\hline Source: UNAIDS. & & \\
\hline
\end{tabular}

complications of gonorrhoea and Chlamydia infections. Consider the enormous sums spent on treating infertility caused by Chlamydia. In a country like Belgium, if you could prevent a few infertility cases per year, you probably have paid back your programme.

STI: "Leadership" is the theme of World AIDS Day 2007. ${ }^{4}$ The journal STI reaches the international STI research community. Does the World AIDS Day theme have a concrete meaning for STI research?

Peter Piot: In the research field, King Holmes is a good example. It is definitely through his leadership that STI have gained scientific respectability. He introduced a scientific approach to study STDs.

Leadership for people working in laboratories? Our point is that leadership is not only something for prime ministers or for the top. It is on all levels. We need a core of people working on STIs, and it is important that young people enter the field, because there is still so much work to be done. I don't think the end is in sight. I would not be concerned about job opportunities.

I think it is important that the scientific community connects with other constituencies. That is the strength of the AIDS movement. You have NGOs, AIDS activists, patients groups, women groups, even business alliances. I think that's what we should try for STI to foster leadership.

STI: During the Toronto World AIDS conference 2006, Bill Clinton gave an example of informal leadership. He praised an Indian woman who got HIV-infected by rape. Instead off hiding herself in shame, she stood up and collaborated in an education programme. ${ }^{5}$ Can UNAIDS foster informal leaders "popping up" from society?

Peter Piot: Fostering informal leadership is one of our main activities. I think it is one of the most important achievements of UNAIDS, to put AIDS on the agenda on various levels: in business, in trade unions, in women's organisations. A few weeks ago, I attended a YWCA conference in Nairobi. Two thousand women were present. It was all on AIDS, with 500 HIV-positive women attending. There you have a Christian organisation of women organising a huge meeting. That's an example of leadership.

How do we do it in practice? Let me give a concrete example. In Djakarta in Indonesia, people with HIV meet in our office. We literally give them space, because they couldn't even rent a room. Owners don't want to have a group of HIV-positive people in their neighbourhood. We had the same thing in Belgium in the 1980s. That's a very downto-earth support of informal leaders. Two weeks ago, I was in China. There are now more and more people with HIV coming out. It is not easy, because of discrimination and stigma. So, we try to offer safe space for people with HIV so that they can come out.

STI: Do you see leadership coming up in MSM (men who have sex with men) communities?

Peter Piot: In the Western world, I see a real decline in leadership on AIDS in the gay community since the introduction of antiretroviral treatment. People see fewer funerals. It is very disappointing, because for sure, leadership in the MSM communities was the driver of the response to AIDS in the eighties.

In other parts of the world, we do see informal leadership coming up. There was a meeting in New Delhi, in September last year. The meeting was on gay groups, homosexuality, whatever you call it, in Asia. It is emerging there. In many countries, homosexuality is against the law. It is not easy. It is problematic to deal with it.

STI: You have mentioned peer pressure. How do African leaders deal with HIV/AIDS?

Peter Piot: Let's put it this way. In 2001, thanks to the action of Kofi Annan and president Obasanjo from Nigeria, things have changed. They called the summit of the African Union. Basically, every African president was there. That broke the taboo. Before 2001, it was extremely difficult for us to work in many countries. We were often accused of exaggerating the problem. Some of the African presidents are really taking on the AIDS issue and show great leadership-President Kagame for example; Mogae in Botswana; or Campaoré in Burkina Faso; or ATT [Amadou Toumani Toure] in Mali. Many other presidents could do much more. STI: UNAIDS developed "Scenarios for Africa 2025". You made a plea to build on emergency actions and put a sustainable response in place. Some critics argue not much seems to have been done.

Peter Piot: It is true. I accept that criticism. We invested a lot of time and brought together many players from outside the AIDS field. The question was if participants could think about the future of AIDS in Africa in 2025. Once the report was out, we have not done enough with it. That is a lesson for us. STI: What are the cornerstones of the "2031 global vision on AIDS"?

Peter Piot: First of all, we have organised discussions with people working in the field. We have identified what they perceived as big challenges. The first challenge everybody mentions is money. Ten billion dollars is attributed to AIDS this year. We have now 2.5 million people on antiretroviral therapy. The big question and challenge is, who will pay for it in 10, 20 years from now? There is quite some interest and money for AIDS now, but is it going to last? These things go with fashion. Climate change is coming up in the global arena. Will the money for AIDS continue? That is the big question. The question is linked with sustainability of leadership and of political commitment. 
The "science and technology" front is another big challenge. What will science and technology bring us the next 25 years, and, more importantly, will we be able to implement new technologies? Science and technology, that's what the ISSTDR conference is about.

Another 2031 group is looking at social drivers and gender inequality. We will have to tackle some of the discrimination issues. It really is a multidisciplinary effort.

From the political arena, G8 leaders are committing themselves now to get as close as possible to universal access of antiretroviral therapy by 2010 . That is defined as $80 \%$ of people who need therapy. By 2010, it means 6 to 7 million people.

STI: How feasible is the "ten by ten" target?

Peter Piot: I think we are not progressing fast enough. At the current pace, there is no way we can reach it. What we see now is that for every person we put on antiretroviral therapy, six new infections occur. That is not sustainable in the long term. We now enrol some 750000 people on antiretroviral therapy each year. That means some 4.5 million people by 2010 . Far from the 2010 goal. STI: Will HIV resistance jeopardise the feasibility of the 2010 target? Is resistance development included in forecasts?

Peter Piot: No. I think that in the short run, resistance development is not going to have an impact, but in the long run, who knows? That's what we are looking at in the 2031 scenarios. Resistance on a large scale doesn't happen in 2 years. On the other hand, in Brazil for instance, the cost of antiretrovirals has doubled over the last 2 years due to the need for second-line therapy.

STI: Some people say there is a disproportion in funding of HIV/AIDS compared with funding of general health problems. Do you agree?

Peter Piot: I agree that there is not enough funding for other health problems. We have seen a certain pattern in several countries. In terms of strengthening of general health services, it only occurs in many countries with AIDS money. These problems are not new. Basically, not much has happened, and with AIDS it is the first time that health services have been strengthened. I can give examples of Malawi or Rwanda, where clinical services have been strengthened.

I agree that more money is needed, not only from international donors, but also from the domestic front. In the Declaration of Abidjan in 2001, there was a commitment to spend $15 \%$ of government budget on healthcare. If all developing countries, if all African countries would indeed spend this percentage of their budget, there would be more money from the domestic front. On the other hand, if all industrialised countries, including Belgium, would spend $0.7 \%$ of their GDP on international development, money would not be the problem.

STI: The Washington Post headlined on July 7 2007: "Experts Reduce Estimate of India's HIV Population by Half". Can you comment on this?

Peter Piot: It is true that there was an overestimate of HIV prevalence in India, but there was no way we could know that. We work with the national authorities. A demographic and health survey was done. It included rural areas, where no sentinel surveillances sites are organised. Indeed, we overestimated it. Our goal is to provide the best possible information. If we have new information, we adapt data. There is no conspiracy that we would overestimate. We have been accused from both sides.

Bill Gates and Richard Feachem, when he was the head of the Global Fund, were saying that India had 10-20 million HIV-positive people. We have always been pretty conservative.

We have reviewed some estimates in Africa. There, the difference was not that big. In India, HIV prevalences are still pretty low, but it is such a huge country. The accuracy of measurements is going to be difficult. Most African countries are small in terms of population. There, the accuracy was much better.

The statement that India has the AIDS problem under control is not true. There is a decline in prevalence in some of the Southern states. That is demonstrated in other ways. In the rest of the country, there are no arguments to demonstrate that AIDS is under control. Plus, you have epidemics in specific populations like drugs users. That's the first point we talked about with government leaders.

Prevalences in India are very diverse. Publishing averages for India is meaningless. You have districts in India with $4 \%$ HIV prevalence. You must count that a district in India is 1 to 2 million people. That's more than [the whole of] Botswana. STI: Has India changed its response to AIDS in the light of these new data?

Peter Piot: In India, there is a new government now with the Congress Party. They have tremendously increased their HIV/AIDS budget. There is a huge World Bank loan. The AIDS response in India is actually fully funded. When the minister of health announced the new HIV figures, a revision downwards, he declared at the same time that their efforts will increase.

Also, with the societies in transition, there is an enormous internal mobility. There are good programs with truck drivers, for instance, the Gates Foundation does some very good work. Up to now, these new data have not had any impact, but you never know. STI: During your presentation, you said that there is much attention on biomedical interventions. Are we forgetting the basics?

Peter Piot: Yes, that's a concern, I have. A month ago, I attended the national AIDS conference in South Africa. Almost all attendees were only talking about male circumcision. Of course, it has been proven to work. It struck me that condoms were hardly ever mentioned. When new research findings are coming up, we have to be careful not to forget the basics. It is not because something new comes up, what works has to be forgotten.

STI: The face of AIDS in Africa is a young woman. Do you see any progress in the empowerment of women.?

Peter Piot: I think you see paradoxical trends. In many sub-Saharan African countries, there is definitely progress in terms of women getting organised. To give an example, there are now programmes against sexual violence in Kenya. South Africa has introduced new laws on sexual 
violence. To be honest, it hasn't changed reality yet, but awareness is growing.

On a general level, things are changing in terms of gender inequality. Rwanda has parity in the government. There are even more women in parliament then men. Uganda also has parity. It is amazing, but these countries are doing better than Belgium and other European countries. In Europe, parity in government only exists in some Nordic countries and in Spain. In terms of gender inequality, we still have a long way to go, that's for sure.

STI: Has corruption with Global Fund money been reported?

Peter Piot: One of the main objectives of the Global Fund is monitoring whether the money is used well. At least two grants that I know have been stopped for reasons of corruption. The dilemma is then what do you do afterwards? The money is needed to keep people alive. Patients are on antiretroviral therapy, and their survival literally depends on the money of the Global Fund. What we usually do then is identify other organisations who can take over. But what do you do when it is the ministry of health, which was the case in both countries?

In UNAIDS, we invest a lot in monitoring and evaluation. In over 50 countries, we have teams monitoring and evaluating the epidemic, not to look for corruption, but it goes with it. We monitor the epidemiology on the one hand, but on the other hand, we measure how many people are on treatment; we evaluate condom promotion. You can of course exaggerate; 10-20\%, I am not sure we would detect. But major corruption would show up. STI: What is the major global health challenge UNAIDS is facing to date?
Peter Piot: The sustainability is the major challenge. It is a combination of what we call in our internal slogan "Making the money work for the people". Ten billion dollars. Does it reach the people who need it and who stay alive with it, or does it get stuck in bureaucracies?

\section{ACKNOWLEDGEMENTS}

I am grateful to Wim Van Damme, Nicola Low, Helen Ward and Filip Moerman, for their advice in the preparation of the interview.

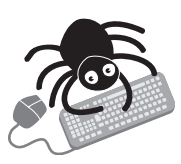

Peter Piot answers more questions in an appendix available on our website at http://sti.bmi.com/ Supplemental

doi: $10.1136 /$ sti. 2007.028100

\section{REFERENCES}

1 ISSTDR and 10th IUSTI World Congress. http://www.isstdr.org (accessed 28 Aug 2007).

2 Piot P. STI and AIDS: Learning from each other for a long-term response. 17th ISSTDR Conference, Seattle, WA, 2007. Slides available at: http://data.unaids.org/pub/Presentation/2007/ isstdr_ppiot_en.pdf (accessed 28 Aug 2007).

3 Piot P. STI and AIDS: Learning from each other for a long-term response. 17th ISSTDR Conference, Seattle, WA, 2007. Speech available at: http://data.unaids.org/pub/SpeechEXD/2007/ 20070821_pp_isstdr_seattle_en.pdf (accessed 20 Aug 2007).

4 World AIDS Day 2007. http://www.worldaidscampaign.info/ index.php/en/wac/keep_the_promise/world_aids_day_2007 (accessed 28 Aug 2007)

5 XVI International AIDS Conference: Global Leaders Speak Out: Mr William Jefferson Clinton and Stephen Lewis, 15 August 2006:18-19. http://www.kaisernetwork.org/health_cast/ uploaded_files/2997-081506_ias_global_transcript.pdf (accessed 30 Aug 2007). 